\title{
Design of New Elevator Pressure Guide Plate and Its Test Device
}

\author{
Qihang Xu ${ }^{1}$, Shaoke Chen ${ }^{2 *}$ \\ ${ }^{1}$ Department of Machinery\& Electric, Jieyang Vocational and Technical College, Jieyang, Guangdong, China \\ ${ }^{2}$ Mechatronic and Electronic Engineering Department, Shantou University, Shantou, Guangdong, China
}

*Corresponding Author: Shaoke Chen, 243 Daxue Road, Shantou, Guangdong, 515063, China; skchen@stu.edu.cn

\begin{abstract}
:
Pressure guide plate plays a certain role in the safe operation of elevator. Based on understanding the respective performance of new and old pressure guide plates, this paper analyses the problems existing in the original pressure guide plate. It also conducts stress analysis according to the function of pressure guide plate on elevator, and designs a new type of pressure guide plate combined with technological capability and equipment. According to the stress characteristics, a test device is designed and a comparative test is made between the new type of pressure guide plate and the old in order to test the reliability of the new type of pressure guide plate. The test proves that the new pressure guide plate of elevator can meet the requirements of product use and safe operation of elevator products.

Keywords: Pressure guide plate; Test device; Guide rails; Elevator

Citation: Q.H. Xu, S.K. Chen, Design of New Elevator Pressure Guide Plate and Its Test Device. Mech Eng Sci, 2019,1(1): 7-13. https://doi. org/10.33142/me.vli1.655
\end{abstract}

\section{Introduction}

Because of the inconvenience of going upstairs and downstairs, elevators have always been the first choice for the public to solve this problem. However, in recent years, injuries caused by elevators have occurred from time to time. Thus, its safety is being questioned. In line with the enterprise mission of "providing safe, comfortable and fast delivery system for human beings", safety is put in the first place for elevator products.

Based on understanding the properties of new and old pressure guide plates, this paper analyses the problems existing in the original pressure guide plates. According to the function of pressure guide plate on elevator, a new type of pressure guide plate is designed, which combines process capability and equipment. According to the stress characteristics, the test device is designed to test the reliability of the new type of pressure guide plate to meet the requirements of the safe operation of elevator products $^{[1]}$.

\section{Design and selection of new elevator pressure guide plate}

2.1 Guide rails and pressure guide plate

Guide rails and pressure guide plate are important components of elevator guidance system. The guide rails provides guidance for the elevator's lifting motion and limits the horizontal movement of the carriage and counterweight ${ }^{[2]}$. Take the carriage as an example. Because the positions of people standing in the car- riage after entering are not fixed, the carriage will incline due to the unbalance loading. The existence of the guide rails limits the occurrence of such excessive inclination, ensuring the stable operation of the carriage and reducing vibration.

Generally speaking, the guide rails are not fixed directly on the wall of the shaft, but on the guide rails bracket, as shown in Figure 1. In order to solve the problems of normal settlement, shrinkage of concrete and deviation of building, the commonly used fixing method is to fix the guide rails on the guide rails bracket with a pressure guide plate, and then connect the guide rails bracket with the pressure guide plate with bolts. The contact between the guide plate and the guide rails is a point contact. When the shaft sinks or the guide rails expand when hot and contracts when cold, and the tension force on the guide rails exceeds the compression force of the pressure guide plate, the guide rails can move relatively to avoid bending deformation ${ }^{[3]}$
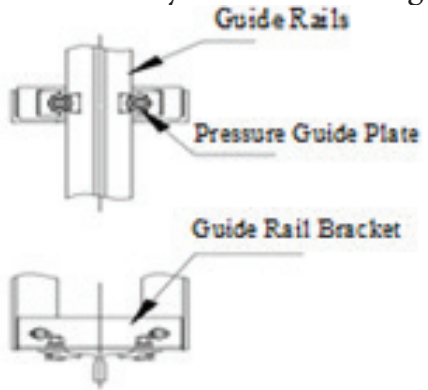

Figure 1. Fixed sketch of guide rails 


\subsection{New pressure guide plate structure}

In elevator industry, the selection of pressure guide plate is generally based on experience. As the guide rails is a standard part, generally speaking, the specific types of guide rails have the corresponding pressure guide plates. A new type of pressure guide plate is designed in a step shape, as shown in Figure 2. The plate body is divided into three parts: front pressure surface, side pressure surface and support surface. The front pressure surface is used to hold down the guide rails. The side pressure surface is used to resist the side edge of the guide rails and reduce the inclination of the elevator. Compared with the old type of pressure guide plate, the side pressure surface of the new type is larger, which is conducive to increasing the stress area. A hole is set in the middle of the supporting surface, which is used to connect the guide rails bracket through the bolt. The upper part of the supporting surface is provided with a bolt locking groove, and the peripheral edge has a side opening. The other edges are inner hexagonal shape corresponding to the shape of bolt head. This shape is easy to install and helps to improve efficiency ${ }^{[4]}$. If the guide plate does not have such grooves, the top of the guide plate is flat. When installing, one wrench must be used to screw the head of the bolt, and another wrench must be used to tighten the nut. Both wrenches need to operate simultaneously. With a groove, the inner hexagonal shape of the groove is the same as a wrench to fix the bolt head. Therefore, the design of the groove improves the installation efficiency.

Compared with the old type of pressure guide plate (Figure $3)^{[5]}$, the structure formed by the front pressure surface and the side pressure surface of the new type fits more closely with the side edge of the pressure guide plate. In use, it can reduce the possibility of micro-movement caused by carriage impact.

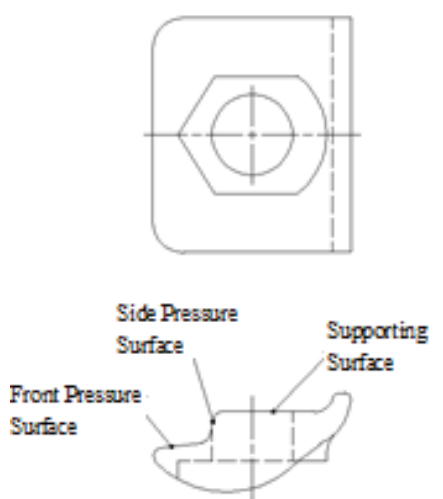

Figure 2. New pressure guide plate

\section{Design of test device}

\subsection{Design thought of test device}

The main function of the pressure guide plate is to limit the displacement of the guide rails in the horizontal direction. Therefore, its force comes from the guide rails. The following conditions exist when the guide rails is subjected to force:

1) The position of the passenger after entering the carriage is not fixed.

2) The cables and compensation chains suspended at the bottom of the carriage are not located at the center of gravity.
3) Because of some devices attached to the carriage (excluding cables and compensation chains), the center of gravity of the carriage is not in the central position.

The above reasons create a reversal trend for the carriage. Thus, they exert a certain force on the top and side of the guide rails.

The analysis shows that the pressure guide plate is subjected to the forces in the $\mathrm{X}$ and $\mathrm{Y}$ directions in the horizontal direction. Therefore, the main principle of the test device is to use a pendulum test (as shown in Figure 4), imitating the position of the guide rails in the shaft, fixed it on the guide rails bracket, and welded the guide rails bracket on the steel frame. At the same time, the gravitational potential energy of the heavy hammer is transformed into kinetic energy to produce the same amount of force as the theoretical analysis above, which indirectly acts on the guide rails. Then the verticality of the guide rails is measured to compare with the verticality of the guide rails specified in the national standard, to measure whether the new type of pressure guide plate can meet the requirements.

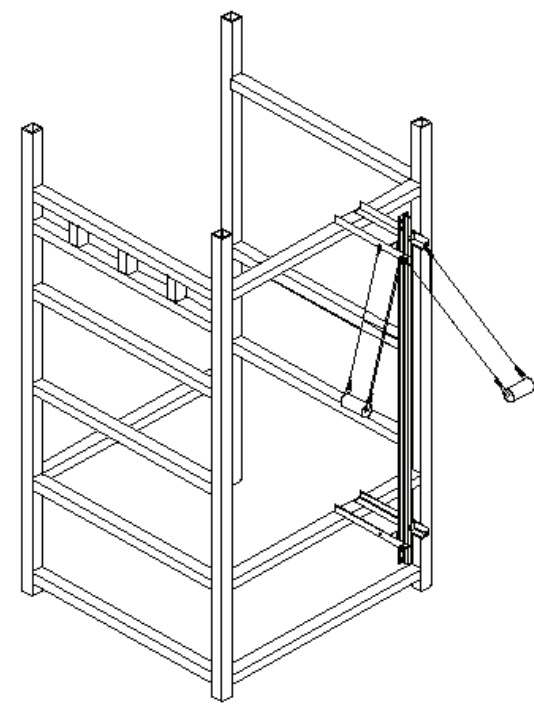

Figure 4. Schematic diagram of the test device

\subsection{Force analysis of guide rails}

The coordinate system of elevator guide rails specified in the national standard is shown in Figure 5. The guide rails is in the direction of $\mathrm{x}$ perpendicular to its side and y perpendicular to its top. When the top view of the carriage bottom is taken as an example (Figure 6), the direction of the opening of the carriage is $\mathrm{x}$ direction, and the horizontal direction of the other one is $\mathrm{y}$ direction ${ }^{[6]}$.

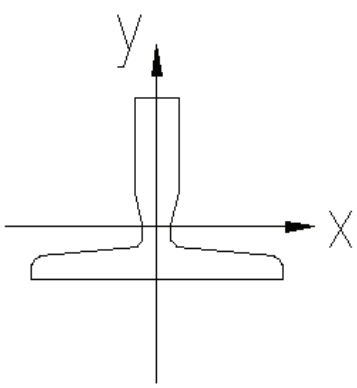

Figure 5. Guide rails coordinate system 


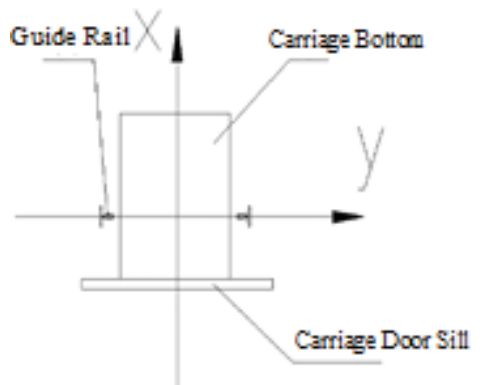

Figure 6. Carriage bottom coordinate system (View from Top)

\subsubsection{Force analysis of guide rails in $x$ direction}

The joint force acting on the guide rails is divided into forces $F_{x}$ and $\mathrm{F}_{\mathrm{y}}$ in the direction of $\mathrm{x}$ and $\mathrm{y}$ by the method of orthogonal decomposition. This section begins with the calculation of $\mathrm{F}_{\mathrm{x}}$. Ideally, the guide rails is not stressed when the elevator is in normal operation. In fact, however, the load distribution of elevators is not even. When the front and rear forces of the carriage are uneven, there will be a reversal trend, which will cause a certain pressure on the guide rails. Especially when the safety clamp are in action, the pressure will be greater. The distribution of load when maximum pressure is exerted on the $\mathrm{x}$-direction of the carriage guide is shown in Figure 7.

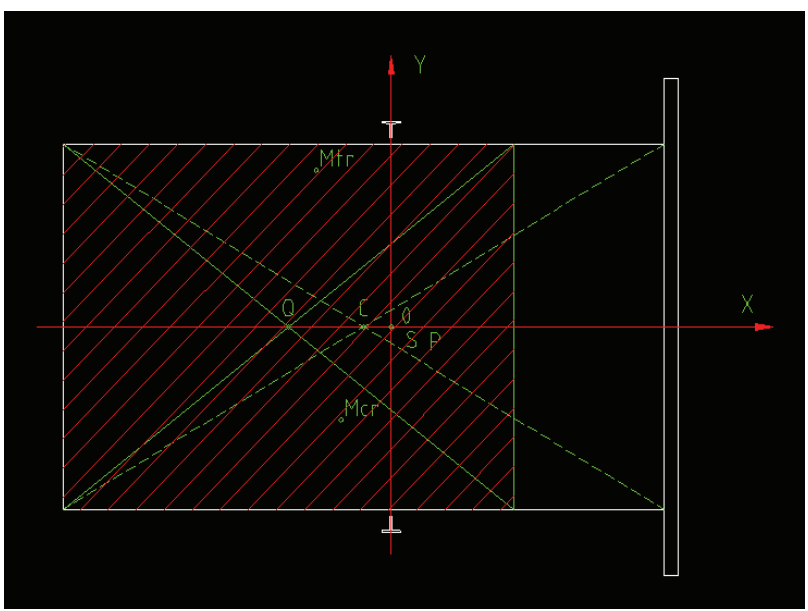

Figure 7. Distribution of gravity center of carriage bottom at maximum $\mathrm{F}_{\mathrm{x}}$

After measuring all the relevant data, the value of $\mathrm{F}_{\mathrm{x}}$ can be calculated. According to the knowledge of torque calculation, when the safety clamp is in action, horizontal force $\mathrm{F}_{\mathrm{x}}$ is produced by the front and rear torque of the carriage.

$F_{X}=\frac{K_{1} g_{\mathrm{n}}\left(\mathrm{Q} \cdot x_{Q}+m_{\mathrm{Mtr}} \cdot x_{\mathrm{Mtr}}+m_{\mathrm{Mcr}} \cdot x_{\mathrm{Mcr}}\right)}{n h}$

In the formula:

$\mathrm{K}_{1}$-- Impact coefficient, determined according to Table G2 on page 70 of Appendix G of GB 7588-2003. Take $K_{1}=2.0$; —Standard gravity acceleration, $9.81 \mathrm{~m} / \mathrm{s}^{2}$.

\subsubsection{Force analysis of guide rails in $y$ direction}

Similarly, when the force is uneven between the left and right of the carriage, the overturning trend will result in the force $F_{y}$ of the guide shoe on the guide rails. The steps are the same as those for solving $F_{x}$. However, it should be noted here is the gravity center when the carriage loads Q located 3/4 to the left of the carriage bottom (at this time, the pressure on the $y$ direction of the guide rails is the greatest). The vertical force on the guide rails is when the carriage is overturned (see Figure 8).

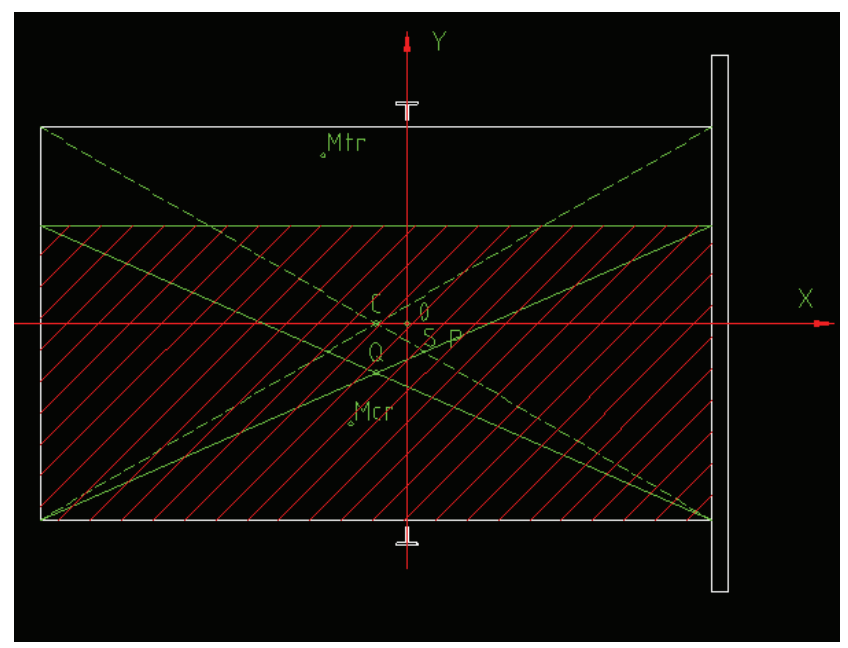

Figure 8. Distribution of gravity center of carriage bottom at maximum $\mathrm{F}_{\mathrm{y}}$

$F_{y}=\frac{K_{1} g_{\mathrm{n}}\left(\mathrm{Q} Y_{Q}-m_{\mathrm{Mtr}} Y_{\mathrm{Mtr}}+m_{\mathrm{Mcr}} Y_{\mathrm{Mcr}}\right)}{\frac{n}{2} h}$

Formula has the same meaning as (1).

\subsubsection{Determination of Fx and Fy}

For the force on the guide rails in the $\mathrm{x}$ direction, assuming that the maximum load of the passenger elevator is $1600 \mathrm{~kg}$, the carriage depth $\mathrm{D}_{\mathrm{x}}=2400 \mathrm{~mm}$, the carriage width $\mathrm{D}_{\mathrm{y}}=1400 \mathrm{~mm}$, and the carriage center of gravity $\mathrm{P}$ is also the suspension point $\mathrm{S}$, the coordinate system is established for the origin. Then $\left(\mathrm{x}_{\mathrm{p}}, \mathrm{y}_{\mathrm{p}}\right)=$ $\left(\mathrm{x}_{\mathrm{s}}, \mathrm{y}_{\mathrm{S}}\right)=(0,0)$, carriage geometric center position $\left(\mathrm{x}_{\mathrm{c}}, \mathrm{y}_{\mathrm{c}}\right)=(-110$, $0)$, rated load gravity center position $\left(\mathrm{x}_{\mathrm{Q}}, \mathrm{y}_{\mathrm{Q}}\right)=(-410,0)$, traveling cable gravity center position $\left(\mathrm{x}_{\mathrm{Mtr}}, \mathrm{y}_{\mathrm{Mtr}}\right)=(300,600)$, compensation chain gravity center position $\left(\mathrm{x}_{\mathrm{Mcr}}, \mathrm{y}_{\mathrm{Mcr}}\right)=(-200,-357)$, distance between guide shoe $\mathrm{H}=3975 \mathrm{~mm}$, guide shoe number $\mathrm{n}$ $=2$, self-weight $\mathrm{P}=1806 \mathrm{~kg}$, compensation chain weight $\mathrm{m}_{\mathrm{Mcr}}=$ $470 \mathrm{~kg}$, traveling cable weight $\mathrm{m}_{\mathrm{Mtr}}=41 \mathrm{~kg}$.

When the safety forceps are in action, the above data are put into formula (1) and the force on the guide rails at the stress point in the $\mathrm{x}$ direction is $\mathrm{F}_{\mathrm{x}} \approx 2138 \mathrm{~N}$.

Similarly, for the force in the $y$ direction at the stress point of the guide rails, except for the center of gravity of the rated load $\left(x_{Q}, y_{Q}\right)=(-110,-175)$, other assumptions are the same. When the safety forceps are in action, the above data are put into formula (2) and the force on the guide rails at the point of force in the $y$ direction is $\mathrm{F}_{\mathrm{y}}=2089 \mathrm{~N}$.

\subsection{Design of test device}

\subsubsection{Principle of Test Pendulum}

The function of the pendulum is to produce a force that is the same as the theoretical analysis to impact the guide rails. The pendulum can be released from a certain height without initial velocity. According to the law of conservation of energy:

$\mathrm{m} g_{n} \mathrm{H}=\frac{1}{2} m v^{2}$ 
Where:

$\mathrm{m}$-Pendulum mass;

$\mathrm{H}-$ Pendulum drop height;

$\mathrm{V}$-Velocity of the pendulum at its lowest point.

From the impulse theorem: $\mathrm{Ft}=\mathrm{mv}$

Where:

F-The impulse of the pendulum on the guide rails;

$\mathrm{t}$-The action time of the pendulum on the guide rails. Here $\mathrm{t}=0.02 \mathrm{~s}$

According to (3) (4), the required mass of the pendulum can be set, and then the drop height of the pendulum can be calculated. In addition, when testing the force condition, the selected measuring point should be the midpoint of the guide rails, because the deformation of the guide rails will be the largest at this time.

\subsubsection{Design and calculation of guide rails bracket}

The guide rails bracket structure of elevator carriage adopts $\Pi$-shaped structure, which belongs to statically indeterminate rigid frame. The original statically indeterminate structure is transformed into statically determinate structure, and unknown forces are added to the statically determinate structure. Then the displacement or deformation of statically determinate structures under the action of loads and unknown redundant forces at the redundant constraints are obtained to satisfy the constraints of the original statically indeterminate structures. The constraints are then transformed into supplementary equations with loads and unknown forces through physical equations. After solving these equations, unknown forces can be obtained, and other unknown forces can be obtained from static equilibrium equations ${ }^{[7]}$.

In order to solve the displacement of guide rails support under the action of $F_{x}$ and $F_{y}$ alone, a unit force should be added at the action point of $F_{x}$ and $F_{y}$ at statically determinate base (where the transverse support is selected as statically determinate base). The unit bending moment diagrams $\mathrm{M}_{\mathrm{PFx}}$ and $\mathrm{M}_{\mathrm{PFy}}$ on statically determinate bases under unit force are also drawn (Figure 9 a) and Figure 9 b)).

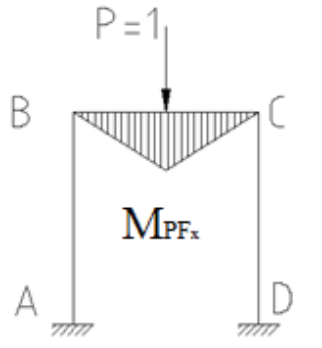

a)

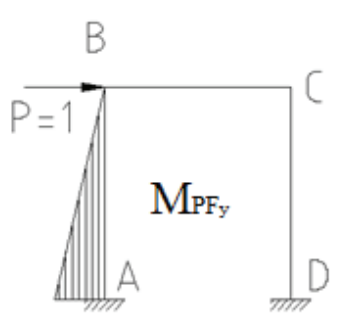

b)
Figure 9. Unit load moment diagram

To solve the displacement of guide rails bracket under the action of $\mathrm{F}_{\mathrm{y}}$ alone, the area of $\mathrm{M}_{\mathrm{PFy}}$ can be multiplied by the coordinates of its centroid position corresponding to the load bending moment diagram of $\mathrm{M}_{\mathrm{Fy}}$ load by graph multiplication ${ }^{[8]}$.

$\Delta F_{y}=2 \times \frac{1}{\mathrm{EI}}\left\{\frac{1}{2} \times \frac{L}{2} \times \frac{L}{4} \times\left[\frac{2}{3} \times\left(\frac{F_{y} L}{4}-\frac{F_{y} L^{2}}{4(\mathrm{H}+2 \mathrm{~L})}\right)-\frac{1}{3} \times \frac{F_{y} L^{2}}{(H+2 L)}\right]\right\}=\frac{F_{y} L^{3}(2 H+L)}{96 E I(H+2 L)}$

Similarly, the displacement of guide rails bracket under the action of $\mathrm{F}_{\mathrm{x}}$ alone can be obtained by graph multiplication.

$\Delta F_{x}=\frac{1}{\operatorname{EI}}\left\{\frac{1}{2} \times H \times H \times\left[\frac{2}{3} \times \frac{F_{x} H(3 H+L)}{2(6 H+L)}-\frac{1}{3} \times \frac{3 F_{x} H^{2}}{2(6 H+L)}\right]\right\}=\frac{F_{x} H^{3}(2 H+2 L)}{12 E I(6 H+L)}$

\section{Experiment and result analysis of test device}

\subsection{Testing device experiment}

The pendulum is used to impact the guide rails according to the set height in turn, and the verticality of the guide rails is used as a benchmark to measure whether the pressure guide rails plate meets the requirements.

Mark the height to which the pendulum will be drawn with chalk on the cart and tie the other end of the pendulum to that height with a rope. Push the cart away until the rope is straightened. After adjusting the pendulum to align its impact plate with the side or top of the guide rails, use the tape to measure whether the gravity center of the pendulum to the ground meets the height requirement. If so, cut the rope with zero speed release and let the pendulum hit the test point. If the verticality of the guide rails after hitting exceeds the requirement of GB/T 100602011 , it is necessary to readjust the verticality of the guide rails. Record the verticality value, and carry out the second pendulum impact test.

When recording the perpendicularity of the guide rails, the pendulum rope is hung above the guide rails. For the $\mathrm{x}$ direction, the deviation between the center of the upper guide rails and the weight line is marked as a value, the deviation between the center of the lower guide rails and the weight line is marked as value $\mathrm{b}$, and the deviation between the guide rails and the weight line is marked as value a-b. For the y direction, the deviation between the top surface of the guide rails and the weight line is marked as value a, the deviation between the lower top surface of the guide rails and the weight line is marked as value $b$, and the deviation of the guide rails is marked as a-b (figs. $10 \mathrm{a}$ ), b)). At the same time, the marking fluid is used at the intersection of the pressure guide plate and the guide rails to confirm whether the guide rails displaces relative to the pressure guide plate after hitting.
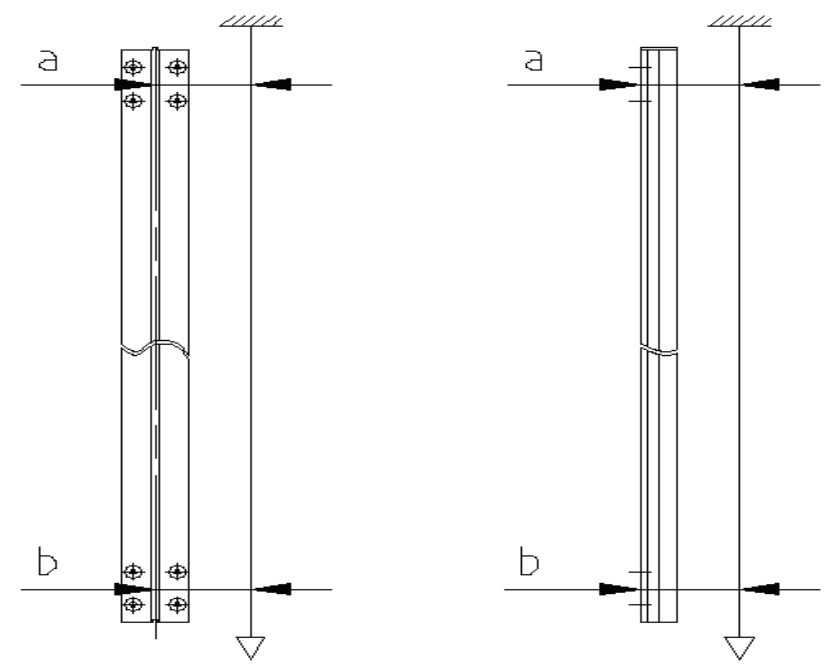

a) Measuring the Perpendicularity of the $x$-direction b) Measuring the Perpendicularity of the $y$-direction

Figure 10. Diagram of Verticality Measurement 


\subsection{Result Analysis}

According to the test results, the verticality of $\mathrm{x}$ and $\mathrm{y}$ directions after impact is sorted out as follows:

According to the theoretical calculation, the double drop height is $711 \mathrm{~mm}$, and the measured value of $\mathrm{x}$-direction pendulum test of guide plate is shown in Table 1.

1) When the drop height is 3 times as high as $1422 \mathrm{~mm}$, the measured values of $\mathrm{x}$-direction pendulum test of guide plate are shown in Table 2.
2)According to the theoretical calculation, the double drop height is $679 \mathrm{~mm}$, and the measured value of $\mathrm{y}$-direction pendulum test of guide plate is shown in Table 3.

3) When the drop height is 3 times as high as $1358 \mathrm{~mm}$, the measured values of $y$-direction pendulum test of guide plate are shown in Table 4.

The verticality data of the guide rails tested in the table are represented by a line chart, as shown in Figure 11.

Table 1. Measured value of $\mathrm{x}$-direction pendulum test of guide plate at $711 \mathrm{~mm}$ drop height

\begin{tabular}{|c|c|c|c|c|c|}
\hline Pressure guide plate type & & Sequence & $a(m m)$ & $\mathbf{b}(\mathbf{m m})$ & a-b $(\mathrm{mm})$ \\
\hline \multirow{6}{*}{ New Pressure Guide Plate } & \multirow{3}{*}{ First Time } & Initial Value & 35.00 & 34.90 & 0.10 \\
\hline & & After Impact & 35.06 & 34.92 & 0.14 \\
\hline & & Change Value & 0.06 & 0.02 & 0.04 \\
\hline & \multirow{3}{*}{$\begin{array}{l}\text { Second } \\
\text { Time }\end{array}$} & Initial Value & 35.06 & 34.92 & 0.14 \\
\hline & & After Impact & 35.14 & 34.92 & 0.22 \\
\hline & & Change Value & 0.08 & 0.00 & 0.08 \\
\hline \multirow{6}{*}{ Old Pressure Guide Plate } & \multirow{3}{*}{ First Time } & Initial Value & 35.68 & 35.37 & 0.31 \\
\hline & & After Impact & 35.77 & 33.54 & 2.23 \\
\hline & & Change Value & -0.09 & 1.83 & 1.92 \\
\hline & \multirow{3}{*}{$\begin{array}{l}\text { Second } \\
\text { Time }\end{array}$} & Initial Value & 35.60 & 35.39 & 0.21 \\
\hline & & After Impact & 35.68 & 32.82 & 2.86 \\
\hline & & Change Value & -0.08 & 2.57 & 2.65 \\
\hline
\end{tabular}

Table 2. Measured value of $\mathrm{x}$-direction pendulum test of guide plate at $1422 \mathrm{~mm}$ drop height

\begin{tabular}{|c|c|c|c|c|c|}
\hline Pressure guide plate type & & ience & $a(m m)$ & $\mathbf{b}(\mathbf{m m})$ & a-b $(\mathrm{mm})$ \\
\hline \multirow{6}{*}{ New Pressure Guide Plate } & \multirow{3}{*}{ First Time } & Initial Value & 39.66 & 39.44 & 0.22 \\
\hline & & After Impact & 37.56 & 36.50 & 1.06 \\
\hline & & Change Value & -2.10 & 2.94 & 0.84 \\
\hline & \multirow{3}{*}{ Second Time } & Initial Value & 38.20 & 37.96 & 0.24 \\
\hline & & After Impact & 37.12 & 35.02 & 2.10 \\
\hline & & Change Value & -1.08 & 2.94 & 1.86 \\
\hline \multirow{6}{*}{ Old Pressure Guide Plate } & \multirow{3}{*}{ First Time } & Initial Value & 35.78 & 35.42 & 0.36 \\
\hline & & After Impact & 35.68 & 27.26 & 8.42 \\
\hline & & Change Value & 0.10 & 8.16 & 8.06 \\
\hline & \multirow{3}{*}{ Second Time } & Initial Value & 35.68 & 35.42 & 0.26 \\
\hline & & After Impact & 35.82 & 27.58 & 8.24 \\
\hline & & Change Value & -0.14 & 7.84 & 7.98 \\
\hline
\end{tabular}

Table 3. Measured value of $y$-direction pendulum test of guide plate at $679 \mathrm{~mm}$ drop height

\begin{tabular}{|c|c|c|c|c|c|}
\hline Pressure guide plate type & & ence & $\mathbf{a}(\mathbf{m m})$ & $\mathbf{b}(\mathbf{m m})$ & $\mathbf{a}-\mathbf{b} \quad(\mathrm{mm})$ \\
\hline \multirow{6}{*}{ New Pressure Guide Plate } & \multirow{3}{*}{ First Time } & Initial Value & 40.32 & 40.28 & 0.04 \\
\hline & & After Impact & 40.32 & 40.28 & 0.04 \\
\hline & & Change Value & 0.00 & 0.00 & 0.00 \\
\hline & \multirow{3}{*}{ Second Time } & Initial Value & 40.32 & 40.28 & 0.04 \\
\hline & & After Impact & 40.32 & 40.28 & 0.04 \\
\hline & & Change Value & 0.00 & 0.00 & 0.00 \\
\hline
\end{tabular}




\begin{tabular}{|c|c|c|c|c|c|}
\hline Pressure guide plate type & & ence & $a(\mathrm{~mm})$ & $\mathbf{b}(\mathbf{m m})$ & $\mathbf{a}-\mathbf{b} \quad(\mathrm{mm})$ \\
\hline \multirow{6}{*}{ Old Pressure Guide Plate } & \multirow{3}{*}{ First Time } & Initial Value & 41.00 & 41.00 & 0.00 \\
\hline & & After Impact & 41.00 & 40.92 & 0.08 \\
\hline & & Change Value & 0.00 & -0.08 & 0.08 \\
\hline & \multirow{3}{*}{ Second Time } & Initial Value & 41.00 & 40.92 & 0.08 \\
\hline & & After Impact & 41.02 & 40.88 & 0.14 \\
\hline & & Change Value & 0.02 & -0.04 & 0.06 \\
\hline
\end{tabular}

Table 4. Measured value of $y$-direction pendulum test of guide plate at $1358 \mathrm{~mm}$ drop height

\begin{tabular}{|c|c|c|c|c|c|}
\hline Pressure guide plate type & & nce & $\mathrm{a}(\mathrm{mm})$ & $\mathbf{b}(\mathrm{mm})$ & $\mathbf{a}-\mathbf{b} \quad(\mathrm{mm})$ \\
\hline \multirow{6}{*}{ New Pressure Guide Plate } & \multirow{3}{*}{ First Time } & Initial Value & 41.50 & 41.30 & 0.20 \\
\hline & & After Impact & 41.50 & 41.32 & 0.18 \\
\hline & & Change Value & 0.00 & 0.02 & -0.02 \\
\hline & \multirow{3}{*}{ Second Time } & Initial Value & 41.50 & 41.32 & 0.18 \\
\hline & & After Impact & 41.52 & 41.32 & 0.20 \\
\hline & & Change Value & 0.02 & 0.00 & 0.02 \\
\hline \multirow{6}{*}{ Old Pressure Guide Plate } & \multirow{3}{*}{ First Time } & Initial Value & 40.32 & 40.00 & 0.32 \\
\hline & & After Impact & 40.32 & 40.04 & 0.28 \\
\hline & & Change Value & 0.00 & 0.04 & -0.04 \\
\hline & \multirow{3}{*}{ Second Time } & Initial Value & 40.32 & 40.04 & 0.28 \\
\hline & & After Impact & 40.33 & 40.03 & 0.30 \\
\hline & & Change Value & 0.01 & -0.01 & -0.02 \\
\hline
\end{tabular}

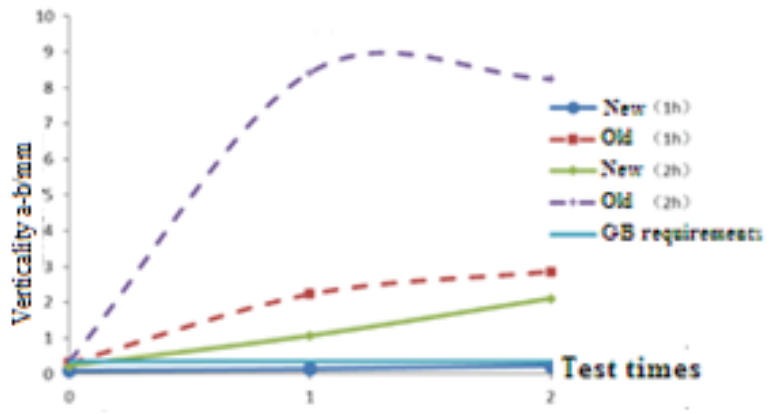

a) Verticality $x$-direction of guide rails test

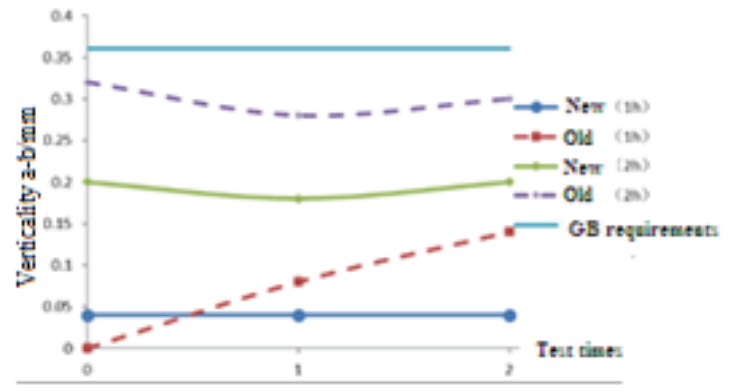

b) Verticality y-direction of guide rails test

Figure 11. Verticality of guide rails test

By comparing the verticality charts above, it can be seen that the verticality of data display is within the requirement when measuring the verticality of $y$ direction of both new and old pressure guide plates. This can be mainly attributed to the support function of the rear guide bracket. In addition, the pressure guide plate will not be loosened or collapsed after the y-axis of the guide is hit forward. For the $\mathrm{x}$ direction, the verticality of the guide rails under the action of two kinds of pressure guide plates has changed obviously, and both of them are in the state of increasing. By comparison, the following two points can be drawn:

1) After impact, the verticality guaranteed by the new type of pressure guide plate is much higher than that of the old type of pressure guide plate. Even if the guide plate is impacted at 3 times the height, the verticality guaranteed by the new type of pressure guide plate is much higher than that of the old type when the guide plate is impacted at double the height.

2) When the pressure guide plate is tested by double height, the verticality of the new type of pressure guide plate is within the prescribed range. However, the verticality of the two types of pressure guides exceeded the requirement after the test was carried out at 3 times the height. Especially the verticality value $\mathrm{a}-\mathrm{b}$ of the old type pressure guides was much higher, which far exceeding the national standard.

\section{Conclusion}

Pressure guide plate plays a certain role in the safe operation of elevator. According to the requirements of safe operation of elevator products and the shape and structure performance of the guide rails, a new type of pressure guide plate is designed and selected in this paper. At the same time, a test device is designed for testing. Through the test, it has been verified that the verticality of the guide rails guaranteed by the new type of pressure guide plate meets the requirements of the national standard when the height is 2 times as high. It not only meets the require- 
ments, but also reduces the cost by two-thirds compared to the old pressure guide plate.

Acknowledgments: The authors wish to thank the special funds for scientific and technological innovation and development in Jieyang, Guangdong (No. 2017xm052) for this project.

\section{References}

[1] SHENG Shichao. Design and Installation of Elevator Locking Device. Equipment Manufacturing Technology [J].2014; 3:194-200.

[2] Zheng wei. Discussion on Installation Quality Detection Technology of Elevator Guide rails Support. Technology Innovation and Application [J]. 2017; 5:100.

[3] Deng yahua. Research on the Connecting Structure of Elevator Guide rails. Science and Technology [J]. 2015; $17: 144$.
[4] Piotr Gołuch, Janusz Kuchmister, Kazimierz Ćmielewski, et al. Multi-sensors measuring system for geodetic monitoring of elevator guide rails. Measurement [J]. 2018; 130:18-31. https://doi.org/10.1016/j.measurement.2018.07.077

[5] Kai Wang, Baoyu Wang, Chuancheng Yang. Research on the Multi-Step Straightening for the Elevator Guide Rail. Procedia Engineering [J]. 2011; 16: 459-466. https://doi. org/10.1016/j.proeng.2011.08.1111

[6] Liu jinyuan. Discussion on Installation and Inspection of Elevator Guide rails Support. China High-Tech Enterprises [J]. 2017; 11:128-129.

[7] National Elevator Standardization Technical Standards Committee. GB/T 22562-2008 Elevator Type T guide rails[S]. Beijing: Standards Press of China, 2008.

[8] Yu chunze. Elevator design calculation and example [M]. Beijing: China Elevator Magazine.2011. 